\title{
Better Learning Online?
}

\author{
Werner Beuschel ${ }^{1}$, Alfred Bork ${ }^{2}$, Chris Hughes ${ }^{3}$, Timothy G. McMahon ${ }^{4}$, Peter \\ Serdiukov ${ }^{5}$, Elizabeth Stacey ${ }^{6}$ \\ ${ }^{1}$ University of Applied Sciences, Brandenburg, Germany; ${ }^{2}$ University of California, Irvine, \\ United States; ${ }^{3}$ University of New South Wales, Australia; ${ }^{4}$ California State University \\ Fullerton, United States; ${ }^{5}$ Kiev State Linguistic University, Ukraine; ${ }^{6}$ Deakin University, \\ Australia
}

Key words: Multimedia Information Systems, Computer Uses in Education

\begin{abstract}
Online learning comes up whenever the issue of improving teaching and learning is mentioned in our current educational institutions. Based on multimedia programs and networked computers, it seems very promising. But as holds true of education anywhere and at any time, no simple blueprint is available to transform educational institutions and the organization of learning processes. So it is legitimate to ask how online learning must be superior to traditional learning and what we should strive actually to achieve. Five panelists (authors ${ }^{2-6}$ ) were asked by the panel organizer (author ${ }^{1}$ ) to present their perspectives to an audience who participated in a lively discussion. This paper is based on statements prepared after the event. Illustrating the range of ideas and experiences that comprise the current state of online learning, this collection also adds an international perspective.
\end{abstract}

\section{THE CHALLENGE OF REALIZING ONLINE LEARNING}

\author{
Werner Beuschel, beuschel@fh-brandenburg.de
}




\subsection{From an enabling technology to better learning environments}

Technological developments like the World Wide Web, multimedia tools, or CD-ROMs are clearly enablers for new ways of teaching and learning. Not surprisingly, a myriad of individual or group efforts in educational institutions aim to capitalize on these opportunities. Consequently, organizations face the dual challenge of integrating new information technologies to enhance learning while providing the appropriate infrastructure to support these technologies.

In addition, traditional forms of education face competition from a number of institutions that label themselves as "online," "distance," "virtual" or even "cyber," and promise to provide easier access to knowledge and certificates via online classes [2]. They argue that online learning has many advantages: (1) temporal independence for individual learners who can choose to study at their own discretion; (2) geographical independence for individual learners who no longer need to commute; and (3) up-to-date materials tailored to individual learners. Options in restructuring efforts include not only the "wired university," but also a completely different approach to the current institutional foundations: This perspective suggests that dot-edu could evolve-or devolve, depending on the reader's point of view, into dot-com.

As a consequence, universities are facing uncertainty on many levels and even confront the suggestion to apply the reengineering approach to solve their "structural and financial crisis" [cf. 6]. Every institution grapples with the dilemma of which strategy to follow and which steps to take. A dearth of data informs their choices. The foreseeable long-term costs of adopting and maintaining a new technology seem to forbid any quick-and-dirty approaches. New technologies are costly, and institutions are loath to commit to several rounds of expenditures with no promise of a viable outcome. And all larger investment plans obviously require steps for funding and stable financing; costs for retraining personnel and marketing cannot be forgotten.

Thus, the current "path" to change in educational institutions is contested terrain and needs public discussion as well as academic clarification. This paper aims to address both aspects. In it, several authors reflect variously on ways to improve learning environments through information and communication technologies. 


\subsection{From individual experiences to a common view}

A host of individual and regional projects have implemented online learning in many countries. Such a list could begin with the famed Open University in the UK, followed by the obviously successful example of the University of Phoenix Online in the US. Nevertheless, how we arrive at possible answers to the organizational and strategic questions is still not clear. In other words, what can we infer from these experiences, limited in time and extent, in order to establish a common understanding about implementing online learning?

The author has been involved in a number of efforts to analyze and to start online learning projects in Germany [cf. 4, 7]. A closer look at these examples reveals that almost no two of them have similar institutional and organizational features. The complexity of educational efforts in them makes it hard to compare. Nor do they easily let us set up categories of strategic approaches. If a main conclusion can be drawn from one national study [4], it shows that the seriousness and the multitude of problems associated with introducing online learning environments must not be underestimated.

So far, we can only point at the advantages or disadvantages of certain approaches. Large-scale projects entail obtaining stable funding sources needed to support retraining personnel and marketing efforts. For this reason, low-budget alliances, even on the level of lecturers, in educational institutions may alleviate the burden of decision making and provide a temporary test bed for experimenting with development options, before further steps are taken [1]. On the other hand, alliances of equal partners seem to foster sustainable results. Local small-scale experiments all too often do not result in integration into the regular teaching process after the individual effort or the funding ends, as institutional or sometimes legal obstacles prevail.

Nevertheless, the difficulties encountered by projects such as the Western Governors University [8] motivate us to continue the search for an analytical framework that will allow us to leverage the data from these efforts. Until then, we should be careful not to put "all our eggs in one basket."

In addition to the difficulties encountered at the organizational level, evidence, though based only on small figures, of students' frustration with the online learning process is beginning to emerge [cf. 3, 5]. This is a reminder to maintain our teaching and learning priorities while using technology.

As we consider the possible outcomes of educational change, it is crucial that we develop a common means of assessing the underlying rationale for these worldwide changes. Not surprisingly, agreement already exists in the form of agreement on disagreement. The following examples help illustrate 
the disparate views of the underlying causes and outcomes of educational change.

Renowned management author, Peter Drucker, predicts an end to academic institutions as we know them:

"Thirty years from now the big university campuses will be relics. ...

The college won't survive as a residential institution."

Xerox PARC researcher, John Seeley Brown, takes another position and focuses on the longstanding tradition of universities and the complex relationship between knowledge, communities, and credentials. He states:

"Institutions of higher education are more likely to be reconfigured than bypassed or abandoned."

Outspoken technology critic and historian, David Noble, decries the reappearance of diploma mills. He applies the metaphor of "digital diploma mills" to question the motives of some players in the field of educational change. Behind the rhetoric of new learning and teaching environments, he assumes the application of rationalization to academic organization:

"The unspoken agenda is to remove direct labor."

\subsection{From pragmatic to analytical questions about online learning}

The following reflections should help frame a more analytical approach to determine contextual issues of online learning. While, for a variety of reasons, a common view. of online learning may be hard to achieve, as discussed above, the need increases for a rational basis for assessing educational change. In addition, we need a basic framework that will provide a basis for making decisions about what to embrace and what to avoid in the development and use of online learning environments.

A list of issues is just a first step towards such a framework, and may provide a common ground for those who want to share different experiences with the transformation of learning. But we believe that the list should emphasize contextual questions, focusing on the interaction of learning with other dimensions. Different lists might include economics, legal issues, curriculum development, policy, or others. In a further move towards a methodology, the potential interactions of these areas must be carefully considered Finally, the concurrent appearance of methodological, organizational, and strategic issues in the implementation process of online learning must be addressed in the framework.

The list here states bilateral relationships and includes questions about (1) learning and technology, (2) learning and pedagogy, (3) learning practices and prerequisites, (4) strategies, and as a consequence of current experiences, (5) next steps: 
1. Learning and technology: Do we agree that using networked information technology will enhance learning? Which learning theories support our view? Is there a difference in learning and learning-to-learn, and should that be reflected in technological support? Is there a dividing line between online and face-to-facelearning?

2. Learning and pedagogy: What is our particular vision of online learning? What is its value added? How do we evaluate and what criteria do we choose? What infrastructure is needed for a crossinstitutional or intra-/international exchange of learning material? Can we leverage existing infrastructures?

3. Learning practices and prerequisites: How different is learning online? What are the prerequisites? What changes are to be made in learning practices? How do we support good existing practices? How do we support acquiring social competence by group-learning processes? How do we prepare students and teachers to learn and teach in online environments?

4. Institutional and organizational strategies: What are appropriate strategies for setting up and supporting online classes in educational institutions? What are distinctive features or guiding principles for a strategy? Are networks better than other approaches? How do educational institutions select appropriate strategies? Are online classes viewed as a supplement or a substitute?

5. Next steps: What are the most controversial issues? Which strategies do not work? Are there any recognizable success factors? Which problems do we want to tackle next?

In the following sections, five authors, affiliated with institutions around the world, present their views on some of the questions above. All the authors are involved in academic or professional decision-making for multimedia use and online learning. As a group, their backgrounds cover areas relevant to the discussion of online learning, e.g. design, use and evaluation of concepts; and the implementation of educational networks within and among universities.

\section{REFERENCES}

[1] Beuschel, W. (1998): Virtual Campus: Scenarios, Obstacles and Experiences. In: Proceedings of the Thirty-First Hawaii International Conference on Systems Sciences (HICSS'31), Vol. I: Collaboration Systems and Technology Track. IEEE Computer Society, Los Alamitos, CA: 284-293 
[2] Business Week (1999): Wiring the Ivory Tower - But will online courses lower standards? European edition, August 9: 58-60

[3] Hara, N. and Kling, R. (1999): Student's Frustrations with a Web-based Distance Education Course: A Taboo Topic in the Discourse. Working Paper. The Center for Social Informatics, Indiana University, Bloomington, IN, www.slis.indiana.edu/CSI/wp99_01.html

[4] Keil-Slawik, R., Klemme, M., Selke, H., Beuschel, W., Gaiser, B. and Pieper, C. (1997): Multimedia in der universitären Lehre - Eine Bestandsaufnahme an deutschen Hochschulen. In: Hamm, I. and Müller-Böling (eds.), Hochschulentwicklung durch neue Medien, Gütersloh: 73-122

[5] The Chronicle of Higher Education (1999): On Line - 2 Professors and Student Offer Mixed Views of Distance Education, August 13, http://www.chronicle.com/free/v45/i49/49a02702.htm

[6] Tsichritzis, D. (1999): Reengineering the University. Communications of the ACM, vol. 42, no. 6: $93-100$

[7] Web page: http://www.fh-brandenburg.de/ beuschel/vfh_index.htm

[8] Western Governors University: http://www.wgu.edu

\section{BETTER LEARNING ONLINE!}

\section{AlfredBork,bork@uci.edu}

We are living in 1937, and our universities . . . are not halfway out of the fifteenth century. We have made hardly any changes in our conception of university organization, education, graduation ... for several centuries. The three or four year course of lectures, the bachelor who knows some, the master who knows most, the doctor who knows all, are ideas that have come down unimpaired from the Middle Ages. Nowadays, no one should end his learning while he lives and these university degrees are preposterous.

H.G. Wells, The World Brain, 1937.

How can online learning improve this situation? I have long suggested the following approaches. Everything suggested is practical and affordable with the interactive technologies of today. Further details are available on the web site [cf. 1]. I will be happy to discuss these points with readers.

Highly interactive learning: Much current learning is passive, whether from lectures, books, video, or web sites. We should insist that learning is active. The student should be a participant in learning, not a spectator.

The following factors characterize highly interactive learning:

a) Conversational: The learning situation should resemble a conversation or dialog. 
b) Like a student-tutor dialog: The model for this computer-based conversation should be the interaction between a student and a skilled tutor.

c) In the student's native language: Our most powerful tool for interaction is our language. Pointing and multiple choice are inadequate for highly interactive learning.

d) Free-form replies: Student replies to frequent computer questions are unrestricted natural language replies.

Individualized: Learning should not be a mass-produced cookie cutter, but should be individualized to the needs, aspirations, and learning style of EACH student. Highly interactive learning makes this possible, if the learning material is reasonably designed.

Different learning for each person: Each person is unique, with unique learning problems.

Programs actively look for student problems: Designers should seek the learning problems that the individual student is having.

Programs offer help for these problems: When problems are found, the program gives aid, and checks to see if that aid is effective.

Testing and learning combined: Testing and learning should be an intimate blend, not separate processes. Tests should be invisible to the student.

Mastery: All students should learn everything, and learn it well.

Small groups working together: Learning is best in groups of about four, local or electronic. Peer learning is valuable.

Full evaluation: All learning material should be fully evaluated by professional evaluators. This should include both formative and summative evaluation.

International development: Learning is not the problem of one country, but of the entire world. So learning units should eventually be in many languages. International design can lead to better learning, and can involve very large numbers.

Distance learning: The primary delivery method for highly interactive learning will be distance learning.

\section{REFERENCES}

[1] http://www.ics.uci.edu/ bork 


\section{CONSTRUCTIVIST LEARNING AND ONLINE TECHNOLOGY}

\section{Elizabeth Stacey, estacey@deakin.edu.au}

My views for creating effective online environments emerge from a framework of cognitive constructivism, particularly, social constructivism. The constructivist view of knowledge, unlike the positivist view of knowledge as "an accumulated body of empirically verifiable facts that are derived directly from observation and experimentation" [1: p.262), perceives its content as constructed by the learner who experiences it. This means that, if knowledge is tentative and socially constructed, it cannot be taught but only learned (or constructed). Many constructivist ideas of learning originate in the work of cognitive psychologists such as Piaget, Bruner and Vygotsky, who share a central notion of constructivism in which the learner has a representational model, a system of schema or personal constructs that provide an anticipatory scheme for the learner to make sense of any situation.

The constructivist perspective implies that the teacher, before teaching, must attempt to understand the learner's existing understandings. Teachers negotiate meaning with learners rather than just transmit content; dialogue is an important part of this process. Guidance and feedback from the teacher ensures that learners are not "'trapped' by their own constructions, without having access to alternative ways of viewing events and ideas" [1: p. 274]. Teachers and course designers in the field of open and distance learning have also been debating the constructivist approach to learning, as an alternative to the more behavioristic model of learning that underpins much of the earlier instructional design of distance learning materials. The use of educational technologies such as Computer Mediated Communication (CMC) as a means of providing the interaction and feedback with teachers and fellow students that facilitate this way of learning, throws into relief the relationship between a constructivist approach, collaborative learning, and learning at a distance.

Cognitive psychologists also emphasize the social nature of learning, particularly when learners are confronted with problems that they cannot solve on their own without the resources of a group. More importantly, the process of discussing, listening to other group members and receiving feedback on ideas, provides the cognitive scaffolding that these constructivists see as essential to higher-order thinking [2: p. 227]. Another concept that has gained acceptance is Vygotsky's notion of a zone of proximal development in which a learner cannot achieve an understanding of a new concept alone and requires help from a teacher or a peer: 
It is the distance between the actual developmental level as determined by independent problem solving and the level of potential development as determined through problem solving under adult guidance or in collaboration with more capable peers [4: p. 86].

Such a concept requires a learner to interact with other learners who will extend his or her understanding. Group interaction in the learning process is an important requirement for this condition and the exploration of Vygotsky's ideas can be used to justify and explain the effectiveness of collaborative learning.

In summary, my pedagogical philosophy for better online learning requires the learner to be considered from a constructivist and social constructivist perspective where:

a) learners construct their own meaning,

b) learners are active and create their own understanding,

c) learning is interactive, needing social interaction,

d) a dialogue is created within a community of learners,

e) learning is a dialectic process to test constructed views, negotiate ideas, collaborate.

\section{Added value}

My research [3] found that students learned online collaboratively by:

a) Sharing the diverse perspectives of the group members.

b) Clarifying their ideas via group communication.

c) Receiving feedback to their ideas from other group members.

d) Seeking group solutions for problems.

e) Practicing the new language of the knowledge community in discussion with other group members before using this language in the whole group or in the new knowledge community.

f) Experiencing the power of group discussion mediated either by communications media or by direct contact.

g) Sharing group resources.

In the social context of group interaction, the collaborative group develops a group consensus of knowledge through communicating different perspectives, receiving feedback from other students and tutors, and discussing ideas, until a final negotiation of understanding is reached. My research study also found that effective collaborative learning in an electronic environment also provides students with:

a) Socio-affective support from the online community; this raised the retention level of student enrollment. 
b) Motivation for learning, because they were accountable to their fellow students for assignment input and received constant feedback as they communicated together.

c) Technical collaboration and support from other group members if they encountered problems learning to use the electronic environment.

d) Multiple modes of communication, because the online communication was often the point of contact for arranging phone conversations or face-to-face meetings, as well as sharing documents and resources by multiple modes of communication.

e) Reflective textual responses that were often more conceptually complex than spoken interactions of a face-to-face group meeting.

f) Improved academic results from those students who had used online learning as a basis for the highest level of communication for group interaction.

\section{Effective strategies}

From researching the practice of innovative teaching staff and from my own online teaching experience, several important strategies for effective teaching in this electronic environment became apparent. CMC was integrated into courses effectively when teachers were able to:

a) structure an authentic use of interaction: the conference was built into the course with conference contributions counting towards assessment;

b) respond to initial student messages: teachers were active in developing group interactivity particularly at the initial stage of the course as the group formed cohesion;

c) act as a group facilitator: students addressed the issues, being guided only as needed;

d) use small groups for large course numbers: collaborative learning was developed through structured tasks that held students accountable both individually and as a group.

\section{REFERENCES}

[1] Candy, P. C. (1991). Self-direction for Lifelong Learning: A Comprehensive Guide to Theory and Practice. San Francisco: Jossey-Bass.

[2] Slavin, R. E. (1994). Student teams-achievement divisions. In Sharan, S. (Ed.), Handbook of Cooperative Learning (pp. 3-19). Westport, CT: Greenwood Press.

[3] Stacey, E. A. (1998). Unpublished doctoral dissertation, Monash University, Melbourne. 
[4] Vygotsky, L. S. (1978). Mind in Society: The Development of Higher Psychological Processes. (Cole, M.M. Lopez-Morillas, Luria, A. R \& Wertsch, J. Trans.). Cambridge, MA: Harvard University Press.

\section{BETTER LEARNING ONLINE - BETTER TEACHING ONLINE}

\section{Chris Hughes, c.hughes@unsw.edu.au}

While addressing the question of how to get better learning online, I want to make a case for the role of the teacher in actively helping learners learn. This approach to online education is not fashionable. I don't think the word "teaching," or the concept of what this might mean in an electronic environment has yet been mentioned at this conference, and we are almost at the end!

To set the theoretical background, I accept most of constructivism's account of learning and its pedagogical implications, for example, that students should be actively engaged in their learning, that they need to relate what they are learning to their experiences and their existing knowledge, and that they need to make the material they are tackling meaningful to them. However, I think that constructivism is careless in its epistemological statements. Its view of knowledge as "subjective and socially constructed," and of the task of learners as being to "construct and negotiate their own meaning" concern me. Such statements amount, in the end, to a poor, if fashionable, epistemology, and they don't accord well with the best practice of teachers or of education. They may capture the views of some in the humanities, but they do not adequately address the task of education in the sciences.

Of course, these views have a kernel of truth in them. Clearly there is a social component in how disciplines construct their accounts of the world, clearly individuals must make sense of what they are learning. However constructivism's formulations imply that consensus within a group amounts to knowledge, and even that we should regard each individual's own unique view as knowledge, regardless of its relationship with the views of others, of the discipline, or with the world. There is much more to most academic disciplines than this. Constructivists speak of negotiation among the community of learners, drawing on a parallel to research communities in a discipline. But there are big differences between the two. Working without the constraints of science, communities of learners can readily agree on very poor accounts of the world, and individuals can misconceive the real state of 
affairs. It happens frequently. It is one of the bases for the need for education, and for the need for teachers.

Constructivists place rightful emphasis on the process of learning, and on learners building their own meanings. But constructivism's weak conception of knowledge leads it to downgrade the goals of education, and teaching almost vanishes in the process. And it vanishes in many implementations of online education too. Indeed, Professor Bork, in his oral contribution to this panel, stated that he wanted to eliminate teachers, or at least the teaching role that most teaching assistants undertake. He saw this role as eminently automatable. For me, the educational role of professors, focused on the communication of content, is the one that may largely be automated. Teaching, real down to earth tutoring, remains one of the most human of activities, one which, because of its dialogic character, will never be fully automated.

These concerns lead me to appreciate Laurillard's very subtle account [3] of teaching and learning in higher education. She manages to work between the poles of instructivism and constructivism, producing an account of teaching and learning that combines largely pre-determined educational goals (as embodied in course objectives and grading criteria, and as represented by the teacher) with a teaching and learning process that demands guidance, persuasion, dialogue, and active engagement in support of the learner. Her "conversational model" of the educational process envisages the dialogue of university teaching as being rhetorical to the extent that the teacher's role is to argue the student into understanding and adopting a position that the discipline, for the whole gamut of reasons inherent in its approach to theory and science, would accept as valid.

For me, much remains for the teaching role after a course of study is instructionally designed, professionally packaged, and fully prepared for online delivery. Teachers work to discover and counter the misconceptions of students as the latter attempt to learn. I take seriously the idea that teaching and learning are social activities, so I am also interested in the use of online group or collaborative learning arrangements, and hence I want to go beyond the one-to-one and one-to- machine models that seem to predominate. I want to teach a group online!

Laurillard has also revived the idea of mathemagenic activities, by which she means activities that engender learning by placing students in situations where they are almost forced to learn. This is an old idea in education, traceable back to Rousseau at least. The idea of mathemagenic activities is common in the design of multimedia packages and programmed learning. It is not so commonly thought of as applying to the areas of teacher-to-student and student-to-student communication. Yet classroom teachers have well 
established mathemagenic techniques that they use in their communication with students to support learning.

Teaching is a form of dialogic communication, and dialogue involves at least two people. But there is more to dialogic teaching than just Socratic questions and answers, much more than the simple exchange of messages, and hence, much, much more than can be accomplished through simple email messaging, chat rooms, and newsgroups.

At UNSW, I have been working with my colleagues on ways of supporting good teaching practice online. We are developing tools and techniques that allow teachers to use the best of their classroom practice to facilitate learning online. This is asynchronous, but synchronised, spontaneous, and responsive teaching. We have developed a web based teaching system that supports a range of communication modes as correlates of the best classroom practice. These are designed as mathemagenic communicative modes, each clearly delineated by a range of structural and graphic markers, each placing mathemagenic demands on students. Currently, the system supports discussion, including meta-comments, questioning with the imposition of a wait time, brainstorming, informal argumentation where students must commit for or against a proposition, formal debates, short answer quizzes with peer review, and case studies. The system, called WebTeach, also allows for anonymity and, to improve participation, notifies the class group by e-mail of all modifications to the web pages.

We have developed this prototype system in stages, monitoring teacher and student use and developing the functionality of the prototype to support and enhance these patterns. The system is now in use in five of our ten faculties, in about 45 teaching groups. It is working well and is easily accepted by both teachers and students. No training in its use is offered, and none seems to be needed. Our evaluations show that this is because the system meshes well with the knowledge base and skills of both teachers and students.

Thus, our strategy in pursuit of better learning online is not to attempt in any way to replace teachers, but to work with them, to support them and their students in the transition to online teaching and learning. We want to make good use of what has been learned about university teaching and learning in the classroom. To do this, we are developing tools and systems that allow teachers and students to employ their finely honed educational skills as they work together online. To achieve good learning online we are supporting good teaching, not eliminating it. 


\section{REFERENCES}

[1] Hewson, L. \& Hughes, C. (1999) An Online Postgraduate Subject in Information Technology for University Teachers. Innovations in Training and Education International, $36,2,106-117$.

[2] Hughes, C., \& Hewson, L. (1998). Online Interactions: Developing a Neglected Aspect of the Virtual Classroom. Educational Technology (July - August), 48-55.

[3] Laurillard, D. (1993). Rethinking University Teaching: a framework for the effective use of educational technology. London: Routledge.

[4] WebTeach demonstration site: http://www.pdc.unsm.edu.au/webteachdemo/welcome.html

\section{INTEGRATING THE CONCEPT OF BETTER LEARNING ONLINE: AN ORGANIZATIONAL PERSPECTIVE}

\section{Timothy G. McMahon, tmcmahon@exchange.fullerton.edu}

The inventions of the book and printing press created a new order of information delivery, education and learning. These inventions have determined the educational process for over four hundred years. This order of books and the printed word are still the foundation of our educational methodologies today. However, the concepts of what it means to be educated and learned have changed. Academic institutions worldwide are experiencing a transformation of information organization and delivery that is rapidly affecting the means people use to obtain an education. This transformation appears inevitable, and is clearly not understood, nor controllable within the academic structures in which we are currently embedded.

Using networked computers for enhanced communication has also led to the delivering of course content, administrative details and functions, and assessment of student efforts in learning new material. Billions of dollars are being invested in building networking infrastructures to support enhanced communications for all operating aspects of existing academic institutions, but the application of the networked computers to the education process is still in its infancy. The technology is changing much faster than the academic institutions are willing (or can afford) to adapt, and any movement towards integrating technology into instruction is met with resistance to change on many levels-faculty, administration and students.

However, the infrastructures are being built and being made functional through large investments, long before faculty are being introduced to instructional design that incorporates networked computers and web-based courseware. (At one large university in California, with approximately 
27,000 students and 1800 faculty, the single largest impediment to the utilization of the new information technology infrastructures is faculty awareness and training. It is not access and it is not outdated equipment or software [cf. 1, 2].) As these "modernized" information technology infrastructures are made operational, the teaching of teachers has lagged far behind what is necessary to utilize the potential of teaching and learning with networked computer enhancement effectively.

As we examine the concept of "better learning online" we must consider the differences in meaning that these words carry to various academic groups. "Better" means that the existing methods and practices are being modified and or changed to exist in an improved state. Thus, are we beginning to examine and assess the effects on student learning outcomes, or are we more concerned with the effects on administrators, faculty, institutions, and budgets? If integrating technology into instruction is better, how is it better? Better learning can mean more access to education for more people than had it before, but is this an improvement in education or simply in numbers? At the same university mentioned above, the millions of dollars spent in creating a fast and functional network for communications has made the Internet and Web available to all faculty and students to a much greater degree than ever before. However, after almost three years of time, money and labor investments, the integration of technology into instruction is being utilized by only approximately one-fifth of the faculty and one-third of the students.

We must also ask what is meant by the concept of "better learning." Is it better to learn through networked computer augmentation where more of the human multiple intelligences can be appeased, but face-to-face interaction potentially is diminished? The methods of assessing the impact of integrated technology with student learning are still using comparison techniques to "seat-time" classes with lecture, testing and semester (or quarter) time frames. The comparisons may have to be made to bring accreditation and acceptance of online teaching and learning to the established institutions of higher education, but the integration of technology into instruction is already changing how many people are receiving an education. This is already occurring to the extent that we must examine the effectiveness of the technology on learning on its own. There are studies showing "no significant difference" when using, or not using, technology in the classroom (in this case television and teleconferencing). However, this is significant in that no difference also means that technology is as good as, and isn't hindering, the existing education process, and is already an alternative to "seat-time" at an educational institution.

The integration of technology into existing educational and institutional practices to build electronic educational environments will escalate. The 
alterations and subsequent enhancements to our communications between teachers and students will also lead to different learning methodologies that will have to be examined for pedagogical usefulness and effectiveness, and simultaneously, assessment of the social, managerial, and institutional impacts upon the students.

It is worthy of study to assess whether it is, indeed, or will become, better learning online.

\section{REFERENCES}

[1] CSU Fullerton Faculty Development Center: http://fdc.fullerton.edu

[2] http://www.ed.gov/Technology/TechConf/1999/whitepapers/paper6.html

\section{THE HUMAN DIMENSION IN A TECHNOLOGICALLY-BASED EDUCATIONAL ENVIRONMENT}

\section{PeterSerdiukov,peterkiy@hotmail.com}

The Human Dimension (HD) - a term coined by Alexander Singer-in a technologically based education can be defined as a system of human-related factors that are involved in the contemporary educational electronic environment (EEE).

It is a universally acknowledged fact that technological innovations stimulate human progress in many aspects. Educational Technology (ET) based on Information and Communication Technologies (ICT) is certainly a powerful and versatile instrument to improve education at all levels. Unfortunately, there is a remarkable mismatch between the technology, predominantly in the form of computer hardware that has been poured into education in the last ten years, and modest achievements in its implementation in classroom settings. Educational Technology has not yet moved from the research domain into the massive application mode. "Computing," as Andries van Dam remarked at this conference, "has not fulfilled its promise." What we can take pride in are really impressive advances in hardware and software development, in global web-based communication and unlimited information access. Many seem to be researching in the area of innovative technologies for education today, but shouldn't we also concentrate on the improvement of educational 
applications of these technologies and on the large-scale use of ET in teaching and learning?

The future of ET and the pace of its implementation in universities depend on many factors, the most critical being a human one. If we consider HD from the learner-centered approach, it may be regarded along the two planes: (1) a vertical-the development of an individual as a human being and a professional: learning how to learn, how to acquire knowledge, how to develop professional skills and competencies, and (2) a horizontal-the development of an individual as a member of the society: learning to live among and with people, to communicate. and to cooperate in team effort. Educational Technology (ET) can be very helpful along both planes, assisting an individual to efficiently learn and develop professionally, and, at the same time, offering him or her new means for interacting with the whole world. If we think about incorporating ET into education, we must focus on the major provider of technological innovations into teaching and learning, that is, on the faculty. What interferes with efficient faculty use of ET in the auditorium on a permanent basis?

The central problem, in my opinion, is the faculty, their training in ET, and stimuli to use it. Besides being overwhelmed with preparation for classes, checking homework, etc., faculty do not get thorough methodological training in ET. For example, the undergraduate ET course offered to student teachers in the universities is usually only 3 credits (45 hours). How, in all good faith, can you cover pedagogical and psychological foundations of ET, learn how to operate the computer, overhead projector, and other equipment, master the methods and techniques of teaching the subject (math, science, language, etc.), and try them out in a real classroom situation in this short time? Practical experience with ET in this course is, evidently, impossible. So, the beginning teacher lacks essential knowledge and skills and is unable fully and effectively to incorporate ET into the classroom. It is no wonder that student teachers are generally dissatisfied with their preparation in ET. These university faculty who did not receive a pedagogical education seem to have no training in ET and its applications at all.

Faculty need to receive a sound undergraduate preparation in the use of ET, then during their professional career be involved in continuous inservice professional development and also have access to qualified expert support in the use of ET. In ET training, as our estimates and experience show, $15 \%$ of the time should be assigned to the theory of ET, 30\% to operational skills, and 55\% to methodological training where the faculty learn how better to teach using ET. We are offering the university faculty an up-to-date professional development program that includes such an ET course and have also developed a continuous 4-year program for the 
preservice teacher in ET training in pedagogical universities that is being implemented in Kiev State Linguistic University [2].

In order to achieve practical, effective results in the large-scale implementation of ET, we absolutely must convert wide masses of faculty into ET-avid users and partisans, increase ET presence in undergraduate teacher training and introduce the ET lifelong learning principle for all school teachers and university faculty focusing on application of the technologies in the teaching/learning process [1]. We must also create a hybrid specialist who would be trained in both technology and general educational and subject matter areas. We must build powerful models of learning and teaching on the basis of new digital multimedia information systems, and create an all-embracing social-technological environment in the universities [2] that would stimulate all the faculty to use ET everywhere it can bring improvement to teaching/learning/research and management. Only then can we expect that the money invested into ET will work.

And last, but not least, about HD, education cannot be limited to professional training only; it is a social institution and process, the integral part of which is to develop citizens who will live and work in the society for its benefit. I cannot agree with my colleague, the most respected Dr. Alfred Bork, who said that he envisions future universities without faculty at all. The ultimate goal of education is to develop a professional who is also an educated person, a human being, a unique individual and a worthy member of human society at the same time. That is why education cannot and should not be totally automated and devoid of the human presence that is so essential for raising the young generation, and for efficient functioning of the EEE as well.

\section{REFERENCES}

[1] Dovgiallo, A., Serdiukov, P. (1997). Integrated Approach to the Development of Distant Learning Environment for Professional Competence Support of a Foreign Language Teacher. In CAL-97. International Conference. The University of Exeter, Great Britain. Conference proceedings: http://www.dcs.ex.ac.uk/cal-97

[2] Serdiukov, P. (1997). Theoretical Foundations of Language Teaching in Universities with Application of Information Technologies. Doctoral Dissertation. Manuscript. Kiev: KSLU. 


\section{ACKNOWLEDGEMENTS}

We especially thank Suzanne K. Schaefer at CORPS/UC Irvine for her great help throughout and after the conference. She clarified many issues by insightful commentaries and provided transcriptions of all the panel contributions. Thanks also to the conference organizers at UC Irvine, in particular Stephen Franklin, for support. 